Jurnal Sastra Indonesia

\title{
TINDAK TUTUR ILOKUSI DALAM WACANA NASKAH DRAMA DELEILAH TAK INGIN PULANG DARI PESTA KARYA PUTHUT E.A.
}

\author{
Novita Indrayanti ${ }^{\bowtie}$, Haryadi, dan Imam Baehaqie
}

Jurusan Bahasa dan Sastra Indonesia, Fakultas Bahasa dan Seni, Universitas Negeri Semarang, Indonesia

\section{Info Artikel}

Sejarah Artikel:

Diterima Januari 2019

Disetujui Februari 2019

Dipublikasikan Maret 2019

\section{Keywords:}

drama script, speech act, and illocutionary

\begin{abstract}
Abstrak
Penelitian ini bertujuan untuk mendeskripsikan dan mengindentifikasi jenis dan fungsi tindak tutur ilokusi yang terdapat dalam wacana naskah drama "Deleilah Tak Ingin Pulang dari Pesta" karya Puthut E.A. Penelitian ini menggunakan pendekatan teoretis yaitu pragmatis dan metodologis yaitu deskriptif kualitatif. Penelitian dilakukan dengan metode simak dengan teknik catat. Hasil penelitian menunjukkan bahwa jenis tindak tutur ilokusi yang terdapat pada wacana wacana naskah drama "Deleilah Tak Ingin Pulang dari Pesta" karya Puthut E.A. adalah (1) tindak tutur representatif meliputi representatif memberitahukan, mengeluh, membanggakan, dan mengakui, (2) tindak tutur direktif meliputi direktif mengajak, memerintah, menasihati, dan meminta, (3) tindak tutur komisif meliputi komisif berjanji, mengancam, dan menawarkan, (4) tindak tutur ekspresif meliputi ekspresif memuji, mengkritik, mengucapkan terima kasih, mengecam, menyindir, menyalahkan, dan mengucapkan selamat, dan (5) tindak tutur isbati meliputi isbati mengundurkan diri dan membatalkan. Adapun fungsi tindak tutur ilokusi yang ditemukan yaitu (1) fungsi kompetitif meliputi kompetitif mengkritik, memerintah, dan membanggakan, (2) fungsi menyenangkan meliputi menyenangkan mengucapkan terima kasih, memuji, mengajak, menawarkan, dan mengucapkan selamat, (3) fungsi bekerja sama meliputi bekerja sama berspekulasi, memberitahukan, mengeluh, melaporkan, mengumumkan, dan mengakui, dan (4) fungsi bertentangan meliputi bertentangan mengancam, mengecam, dan menyalahkan.
\end{abstract}

\begin{abstract}
This study aims to describe and identify the types and functions of illocutionary speech acts contained in the drama script discourse "Deleilah Tak Ingin Pulang dari Pesta” by Puthut E.A. This study uses a theoretical approach that is pragmatic and methodological which belong to descriptive qualitative. This research was carried out by using scrutinized method and note technique. The results of this research showed that the type of illocutionary speech acts contained in the discourse plays "Deleilah Tak Ingin Pulang dari Pesta " by Puthut E.A. were: (1) the representative speech acts include the representative of telling, complaining, boasting, and recognizing, (2) the directive speech acts include directive of inviting, instructing, advising, and asking, (3) the commissive speech acts include commissive of promising, threatening, and offering, (4) the expressive speech acts include expressive of praising, criticizing, thanking, inveighing, teasing by illusion, blaming, and congratulating, and (5) the isbati speech acts include the isbati of resigning and canceling. The functions of illocutionary speech acts which were found were: (1) the function competitively includes the competitive of criticizing, commanding, and encouraging, (2) the pleasing functions include pleasing to thank, praise, encourage, offers, and congratulate, (3) the functions of work in team include working in team to speculate, inform, complain,
\end{abstract}


Novita Indrayanti/ Jurnal Sastra Indonesia 8 (1) (2019)

report, announce and acknowledge, and (4) the contradict function includes contradictory threatening, critical, and blame.

(C) 2019 Universitas Negeri Semarang

Alamat korespondensi:

ISSN 2252-6315

Gedung B1 Lantai 1 FBS Unnes

Kampus Sekaran, Gunungpati, Semarang, 50229

E-mail: novitaindra359@gmail.com 


\section{PENDAHULUAN}

Bahasa dan manusia merupakan dua hal yang tidak dapat dipisahkan. Seseorang akan dapat mengungkapkan perasaan, pikiran, dan keinginannya kepada orang lain dengan bahasa. Dalam berinteraksi tersebut terjadi sebuah komunikasi yang merupakan suatu rangkaian kegiatan berbahasa yang disebut tindak tutur atau speech act. Tindak tutur merupakan satuan yang bersifat sentral dalam pragmatik karena tanpa adanya suatu tindak tutur, kajian dalam pragmatik tidak berhasil dengan baik. Pada waktu mengucapkan suatu tuturan tidak semata-mata mengatakan sesuatu dengan mengucapkan tuturan itu, tetapi di dalam mengucapkan suatu tuturan ia juga menindakkan sesuatu. Hal tersebut didukung oleh pendapat yang dikemukakan oleh Tarigan (1990:36), bahwa ucapan dianggap sebagai suatu bentuk kegiatan (suatu tindak ujar). Tindak tutur mempunyai jenis, fungsi pragmatis dan kadang-kadang terdapat juga prinsip percakapan. Jenis tindak tutur meliputi, tindak tutur lokusi, ilokusi, dan perlokusi. Berbeda dengan lokusi dan perlokusi, tindak tutur ilokusi tidak mudah diidentifikasi. Hal itu terjadi karena ilokusi itu berkaitan dengan siapa bertutur kepada siapa, kapan dan di mana tindak tutur itu dilakukan, dan sebagainya (Rustono 1999:36). Dengan demikian tindak ilokusi merupakan bagian terpenting untuk memahami tindak tutur. Karena itulah tindak tutur ilokusi perlu dikaji lebih dalam lagi agar tindak tutur dapat dipahami dengan baik.

Searle (dalam Tarigan 1990) membagi tindak ilokusi menjadi lima, yaitu (1) representatif, (2) direktif, (3) komisif, (4) ekspresif, dan (5) isbati. Selain kelima jenis tersebut, tindak ilokusi juga memiliki empat fungsi, yaitu (1) fungsi kompetitif, (2) fungsi convival (menyenangkan), (3) fungsi kolaboratif (bekerja sama), dan (4) fungsi konfliktif (bertentangan) (Leech 2011:161).

Tuturan ilokusi di dalam kehidupan tidak hanya terdapat dalam bahasa lisan, tetapi juga dalam bahasa tulis. "Deleilah Tak Ingin Pulang dari Pesta" karya Puthut E.A. merupakan jenis bahasa tulis berbentuk naskah drama yang di dalamnya terdapat percakapan waria. Drama ini baik untuk dikaji karena mengandung berbagai jenis dan fungsi tindak tutur ilokusi.

\section{METODE PENELITIAN}

Pendekatan yang digunakan dalam penelitian ini adalah pendekatan secara teoretis dan metodologis. Secara teoretis menggunakan pendekatan pragmatis dan secara metodologis menggunakan pendekatan deskriptif kualitatif. Data penelitian ini berupa penggalan-penggalan wacana dalam naskah drama Deleilah Tak Ingin Pulang dari Pesta karya Puthut E.A. yang diasumsikan mengandung tuturan ilokusi. Sumber data pada penelitian ini adalah wacana yang ada dalam naskah drama Deleilah Tak Ingin Pulang dari Pesta karya Puthut E.A.

Pendekatan yang dilakukan dalam penelitian ini ada dua yaitu secara teoretis menggunakan pendekatan pragmatis dan secara metodologis menggunakan pendekatan deskriptif kualitatif. Metode pengumpulan data penelitian ini yaitu metode simak kemudian dilanjutkan dengan teknik catat yakni mencatat dalam kartu data yang telah dibuat. Metode analisis data penelitian ini yaitu menggunakan metode heuristik yaitu jenis tugas pemecahan yang dihadapi penutur dalam menginterpretasi sebuah tuturan atau ujuran (Leech 1993:61). Selanjutnya, hasil analisis data dalam penelitian ini disajikan dengan metode informal. Metode pemaparan hasil secara informal adalah pemaparan dengan kata-kata (Sudaryanto 1993:63).

\section{HASIL PENELITIAN}

Hasil penelitian menunjukkan bahwa jenis tindak tutur ilokusi yang terdapat pada wacana wacana naskah drama "Deleilah Tak Ingin Pulang dari Pesta" karya Puthut E.A. adalah (1) tindak tutur representatif meliputi representatif memberitahukan, mengeluh, membanggakan, mengakui, dan menuntut, (2) tindak tutur direktif meliputi direktif mengajak, memerintah, menasihati, dan meminta, (3) tindak tutur komisif meliputi komisif berjanji, mengancam, dan menawarkan, (4) tindak tutur ekspresif meliputi ekspresif mengucapkan terima kasih, memuji, mengkritik, mengecam, menyindir, menyalahkan, dan mengucapkan selamat, dan 
(5) tindak tutur isbati meliputi isbati mengundurkan diri dan membatalkan. Adapun fungsi tindak tutur ilokusi yang ditemukan yaitu (1) fungsi kompetitif meliputi kompetitif mengkritik, memerintah, membanggakan, dan menuntut, (2) Fungsi menyenangkan meliputi menyenangkan mengucapkan terima kasih, memuji, mengajak, menawarkan, dan mengucapkan selamat, (3) fungsi bekerja sama meliputi bekerja sama berspekulasi, memberitahukan, mengeluh, melaporkan, mengumumkan, dan mengakui, dan (4) fungsi bertentangan meliputi bertentangan mengancam, mengecam, dan menyalahkan.

1. Jenis Tindak Tutur Ilokusi dalam Wacana Naskah Drama Deleilah Tak Ingin Pulang dari Pesta Karya Puthut E.A.

Wijana (1996:18) mengatakan bahwa sebuah tuturan selain berfungsi untuk mengatakan atau menginformasikan sesuatu, dapat juga dipergunakan untuk melakukan sesuatu. Bila hal ini terjadi, tindak tutur yang terbentuk adalah tindak ilokusi. Searle (dalam Tarigan 1990) membagi tindak ilokusi menjadi lima, yaitu (1) representatif, (2) direktif, (3) komisif, (4) ekspresif, dan (5) isbati.

Berikut ini merupakan contoh penggalan wacana dalam naskah drama Deleilah Tak Ingin Pulang dari Pesta" karya Puthut E.A. yang termasuk tindak tutur representatif memberitahukan.

KONTEKS : ROSIANA BERTANYA TENTANG KEBERADAAN HAPPY DAN LUNA KARENA TIDAK ADA DI TEMPAT MANGKAL.

Rosiana : Happy dan Luna mana?"

Dina: Ah, Mbak Rosi seperti enggak tahu saja. Mereka berdua kan sudah jarang nyebong (mangkal). Kata Derby sih, Luna mulai sibuk ketemu produser..."

(Data 2)

Tuturan " Mereka berdua kan sudah jarang nyebong (mangkal). Kata Derby sih, Luna mulai sibuk ketemu produser, dituturkan untuk memberitahukan pandangan tentang kenyataan sesuai dengan pemahaman penutur. Tuturan tersebut juga mengikat penutur akan kebenaran atas apa yang diujarkannya, yaitu Luna dan Happy sudah jarang mangkal dan Derby mengatakan Luna mulai sibuk bertemu dengan produser. Kebenaran tuturan tersebut dapat diperoleh dari kenyataan bahwa Luna dan Happy memang sudah jarang mangkal dan Derby memang mengatakan Luna mulai sibuk bertemu produser. Tuturan tersebut dimaksudkan penutur untuk memberitahu mitra tutur agar tidak mencari Happy dan Luna lagi. Disebut memberitahukan karena penutur menyampaikan informasi agar diketahui oleh mitra tutur.

Berikut ini merupakan contoh penggalan wacana dalam naskah drama Deleilah Tak Ingin Pulang dari Pesta karya Puthut E.A. yang termasuk tindak tutur direktif mengajak.

$$
\begin{aligned}
& \text { KONTEKS : ANA DAN ANI MASIH } \\
& \text { BINGUNG DENGAN PERKATAAN } \\
& \text { DIAN. } \\
& \text { Ana } \quad \text { : Eh,kalau tadi semua } \\
& \text { salah, terus yang betul } \\
& \text { siapa?" } \\
& \text { Ani : Apanya?" } \\
& \text { Ana : Itu tadi, ada polandia ada } \\
& \text { gula teh..." } \\
& \text { Ani } \quad \text { : Embuh! Ayo ke staf } \\
& \text { keuangan, ambil } \\
& \text { perdiem!"” }
\end{aligned}
$$

(Data 4)

Tuturan "Ayo ke staf keuangan, ambil perdiem!, dituturkan penutur untuk membuat pengaruh agar mitra tutur melakukan tindakan-tindakan yang dikehendakinya melalui ujaran ajakan. Penutur mengajak mitra tutur pergi ke staf keuangan untuk mengambil uang perdiem. Indikator bahwa tuturan itu direktif adalah adanya tindakan yang harus dilakukan oleh mitra tutur setelah mendengar tuturan itu, yaitu pergi ke staf keuangan bersama penutur untuk mengambil uang perdiem. Tuturan tersebut juga dimaksudkan penutur agar mitra tutur tidak membahas lagi masalah dalam diskusi. Disebut mengajak karena penutur meminta mitra tutur untuk ikut dengannya ke staf keuangan dengan ditandai kata ayo.

Berikut ini merupakan contoh penggalan wacana dalam naskah drama Deleilah Tak Ingin Pulang dari Pesta karya 
Puthut E.A. yang termasuk tindak tutur komisif menawarkan.

KONTEKS : DIAN MENAWARKAN KEPADA PARA WARIA UNTUK MULAI MASUK KE DUNIA POLITIK.

Dian: Nah, balik lagi ke soal tadi. Itu penting lho. Bener. Kalau kalian tertarik, nanti kubantu bikin proposalnya. Dan kubantu carikan dananya"

(Data 25)

Tuturan " Kalau kalian tertarik, nanti kubantu bikin proposalnya. Dan kubantu carikan dananya, dituturkan penutur dengan maksud mengikat dirinya untuk melakukan tindakan-tindakan di masa yang akan datang melalui ujaran penawaran. Penutur menawarkan bantuan untuk membuat proposal dan mencarikan dana jika mereka tertarik untuk masuk ke dunia politik. Penutur menawarkan demikian agar mitra tutur bersedia masuk ke dunia politik. Disebut menawarkan karena penutur menunjukkan sesuatu kepada mitra tutur dengan maksud agar bantuannya bisa diterima.

2. Fungsi Tindak Tutur Ilokusi dalam Wacana Naskah Drama Deleilah Tak Ingin Pulang dari Pesta" Karya Puthut E.A.

Situasi-situasi yang berbeda menuntut adanya jenis-jenis dan derajat sopan santun yang berbeda juga. Pada tingkatan yang paling umum, fungsi-fungsi ilokusi dapat diklasifikasi menjadi empat jenis, sesuai dengan hubungan fungsi-fungsi tersebut dengan tujuan-tujuan sosial berupa pemeliharaan yang sopan dan terhormat (Leech 2011:161).

Berikut ini merupakan contoh penggalan wacana yang termasuk dalam fungsi kompetitif dengan verba menuntut.

KONTEKS : HAPPY DAN LUNA MENUNTUT PENJELASAN MENGENAI MASALAH METRO YANG AKAN DITUTUP DARI DEDI.

Luna : Benarkah, Mas?"

Happy : Kenapa mas enggak cerita ke ike?! Mas Dedi diskriminatif!"

Dedi: Sudah ah! Asal kalian

tahu saja, bukannya aku seperti itu, tetapi aku waktu untuk

membicarakan hal ini. Kalian apa-apaan! Hanya masalah seperti ini saja seperti aku tidak adil membagi uang saja!"

(Data 14)

Tuturan " Kenapa mas enggak cerita ke ike?! Mas Dedi diskriminatif!, dituturkan penutur untuk menuntut hak yang sama dari Dedi. Penutur menuntut hak dari Dedi karena tidak mendapat penjelasan mengenai masalah Metro yang akan ditutup. Pada tuturan tersebut sopan santun mempunyai bentuk negatif, karena penutur menyampaikan tuturan tersebut dengan tidak bertata krama kepada Dedi. Disebut menuntut karena penutur berusaha keras untuk mendapatkan hak yang sama dari Dedi yaitu mendapatkan penjelasan tentang masalah Metro.

Berikut ini merupakan contoh penggalan wacana yang termasuk dalam fungsi menyenangkan dengan verba memuji.

KONTEKS : DIAN MEMUJI BRIAN AGAR IA BERSEDIA MASUK KE DUNIA POLITIK.

Brian : Waduh...Aku belum

Dian: Ayolah, Mas. Aku kepikiran hal itu..." perhatikan dari lama, Mas Brian ini cocok lho mulai masuk ke dunia politik.

Penampilan oke.

Pemikiran cemerlang.

Modal uang juga punya.

Nanti bisa aku back up deh

Mas..."

Pada penggalan wacana di atas terkandung fungsi menyenangkan dengan verba memuji. "Aku perhatikan dari lama, Mas Brian ini cocok lho mulai masuk ke dunia politik. Penampilan oke. Pemikiran cemerlang. Modal uang juga punya. Nanti bisa aku back up deh Mas, penutur menuturkan demikian untuk memuji Brian. Penutur memuji Brian sebagai orang yang memenuhi semua syarat untuk masuk ke dunia politik, yaitu berpenampilan baik, mempunyai pemikiran cemerlang, dan modal uang yang ia miliki. Tuturan yang diujarkan oleh penutur mengandung nilai sopan santun yang bersifat 
positif dan tujuan penutur adalah mencari kesempatan untuk beramah-tamah dengan cara memberi pujian. Disebut memuji karena penutur menunjukkan kekaguman dan penghargaan kepada mitra tutur yang dianggap memenuhi syarat untuk masuk ke dunia politik.

Berikut ini merupakan contoh penggalan wacana yang termasuk dalam fungsi bertentangan dengan verba mengancam.

KONTEKS: BERTA, BERTI, ROSIANA, DAN DEDI MENUNGGU HAPPY DAN LUNA UNTUK LATIHAN.

$\begin{array}{ll}\text { Dedi } & \text { : " Sabar ya...” } \\ \text { Berta } & \text { : " Iya, ike sih sabar-sabar aja. } \\ & \text { Toh kalau ada apa-apa, bukan } \\ & \text { ike yang tanggung! Mereka } \\ & \text { sendiri yang harus } \\ & \text { menanggungnya!" }\end{array}$

Dedi : Jangan gitu dong, Berta...'

(Data 8)

Tuturan tersebut merupakan tindak tutur ilokusi yang memiliki fungsi bertentangan, dengan verba mengancam. Tuturan tersebut memiliki tujuan yang bertentangan dengan tujuan sosial yaitu mengancam dan direncanakan untuk menimbulkan pelanggaran. Penutur mengancam Happy dan Luna yang terlambat latihan, jika terjadi sesuatu penutur tidak ingin menanggungnya, tetapi mereka sendiri yang harus menganggungnya. Dalam tuturan tersebut sopan santun tidak ada sama sekali, karena tuturan mengancam tidak mungkin disampaikan dengan sopan. Disebut mengancam karena penutur memberi pertanda atau peringatan mengenai kemungkinan buruk yang akan terjadi.

\section{SIMPULAN}

Berdasarkan pembahasan tersebut dapat penulis simpulkan bahwa jenis tindak tutur ilokusi dalam wacana naskah drama "Deleilah Tak Ingin Pulang dari Pesta" karya Puthut E.A. yaitu tindak tutur ilokusi representatif, direktif, komisif, ekspresif, dan isbati. Tindak tutur ilokusi representatif meliputi representatif memberitahukan, mengeluh, membanggakan, mengakui, dan menuntut. Tindak tutur ilokusi direktif meliputi direktif mengajak, memerintah, menasihati, dan meminta. Tindak tutur ilokusi komisif meliputi komisif berjanji, mengancam, dan menawarkan. Tindak tutur ilokusi ekspresif meliputi ekspresif mengucapkan terima kasih, memuji, mengkritik, mengecam, menyindir, menyalahkan, dan mengucapkan selamat. Tindak tutur ilokusi isbati meliputi isbati mengundurkan diri dan membatalkan. Adapun fungsi tindak tutur ilokusi dalam wacana naskah drama "Deleilah Tak Ingin Pulang dari Pesta" karya Puthut E.A. yaitu fungsi kompetitif, menyenangkan, bekerja sama, dan bertentangan. Fungsi kompetitif meliputi kompetitif mengkritik, memerintah, membanggakan, dan menuntut. Fungsi menyenangkan meliputi menyenangkan mengucapkan terima kasih, memuji, mengajak, menawarkan, dan mengucapkan selamat. Fungsi bekerja sama meliputi bekerja sama berspekulasi, memberitahukan, mengeluh, melaporkan, mengumumkan, dan mengakui. Fungsi bertentangan meliputi bertentangan mengancam, mengecam, dan menyalahkan.

\section{DAFTAR PUSTAKA}

Leech, Geoffrey. 1983. The Principle of Pragmatics. Terjemahan ke dalam Bahasa Indonesia dilakukan oleh M.D.D. Oka. 1993. Prinsip-Prinsip Pragmatik. Jakarta: UI Press.

Rustono. 1999. Pokok-Pokok Pengajaran Pragmatik. Semarang: IKIP Semarang Press.

Sudaryanto. 1993. Metode dan Aneka Teknik Analisis Bahasa. Yogyakarta: University Press.

Tarigan, Henry Guntur. 1990. Pengajaran Pragmatik. Bandung: Angkasa.

Wijana, I. Dewa Putu. 1996. Dasar-Dasar Pragmatik. Yogyakarta: Andi. 